\title{
Orientation cues and mechanisms used during avian navigation: A review
}

\author{
Tushar Tyagi \\ Department of Zoology, Ch. Charan Singh University, Meerut - 250004 (Uttar Pradesh), India \\ Sanjay Kumar Bhardwaj* \\ Department of Zoology, Ch. Charan Singh University, Meerut - 250004 (Uttar Pradesh), India \\ *Corresponding author. E mail: drskumar7@yahoo.com
}

\section{Article Info}

https://doi.org/10.31018/ jans.v13i2.2684

Received: April 18, 2021

Revised: May 26, 2021

Accepted: May 29, 2021

\section{How to Cite}

Tyagi, T. and Bhardwaj, S. K. (2021). Orientation cues and mechanisms used during avian navigation: A review. Journal of Applied and Natural Science, 13(2), 627 - 640. https://doi.org/10.31018/jans.v13i2.2684

\begin{abstract}
The navigational systems of different animal species are by a wide margin less notable as compared to birds. Humans have been interested in how migratory birds discover their way more than thousands of miles for quite a long time. This review summarizes the cues and compass mechanisms applied in orientation and navigation by non-migrants, diurnal and nocturnal migrants. The magnetic compass, landmarks, olfactory, and memory of spatial cues en route were utilized in homing and migration. The equivalent is valid for the sun compass despite the fact that its job during migration might be undeniably less significant than commonly presumed. Stellar compass and celestial rotation, as a result of their nighttime accessibility, appear to influence the direction of nighttime migrants during the course of migration. The celestial cues go through notable changes because of the latitude shift during bird migration. Sunset cues alter their location with seasons and latitudes. The recognizable stars lose height and lastly vanish underneath the horizon, whereas new stars show up. These new ones must be calibrated. As celestial rotation not imparting a reference, it is not unexpected that the magnetic compass turns into the main cue that controls the directional importance of stars and sunset cues. Field studies have revealed that, in certain species, a considerable extent of individuals get back to similar breeding, overwintering, and stopover areas in progressive years. This review proposes that migratory birds have advanced uncommon cognitive capacities that empower them to achieve these accomplishments.
\end{abstract}

Keywords: Birds, Compass mechanisms, Cues, Navigation, Orientation

\section{INTRODUCTION}

To finish their long journeys, migratory birds have created expound capacities to recognize several sensory cues, in order to incorporate such signals inside the nervous system, with a view to apply them as a component of exceptionally proficient navigation techniques (Alerstam et al., 2011; Gagliardo et al., 2013; Holland, 2014; Mouritsen et al., 2016). Subsequently, their navigational ability should be inborn or learned prior to their first take-off (Schmaljohann et al., 2012; Mouritsen, 2015). After having finished one complete journey, numerous adult birds can explore with extreme accuracy of centimetres across a long distance of $5,000 \mathrm{~km}$ or more (Salewski et al., 2000). Studies have demonstrated the potential for geomagnetic bi-coordinate map navigation across various regions of the world by investigating the difference in angles between isolines of earth's magnetic field strength and magnetic inclination.
Within 'no-grid' regions isolines run practically parallel, an effective magnetic bi-coordinate navigational strategy wouldn't be achievable (Boström et al., 2012). The 'orientation' implies that only the headings for migration are being established. To achieve 'true navigation', birds first require to decide their current map location after which the compass route towards the destination. True navigators could compensate for the displacement throughout their trip (Grifn, 1952; Chernetsov et al., 2008; Holland, 2014). Experienced birds going on migration for subsequent seasons post their first year of migration encountered cue transitions which created a map to compensate for the displacement towards obscure areas. That way, they can carry out true navigation (Kishkinev et al., 2013; Holland, 2014; Mouritsen, 2015; Chernetsov et al., 2017). Inexperienced songbirds that migrate at night have innate instincts to their migratory heading and distance (Berthold, 1999), yet the genes supporting this have not been recognized 
Tyagi, T. and Bhardwaj, S. K. / J. Appl. \& Nat. Sci. 13(2), 627 - 640 (2021)

(Ramos et al., 2017).

Many skilled migratory birds have evolved substantial scale maps, likely multi-coordinate and multi-sensory, that could be assumed to compensate for the displacement in an unusual location (Gagliardo et al., 2013; Holland, 2014; Mouritsen, 2015; Chernetsov et al., 2017). It is typically presumed that to compensate displacements in an unfamiliar region, birds accumulate statistics in their yearly distribution range, analyse anticipated spatial gradient of natural environment cues inside it, and conclude from the ones to unknown magnitudes - the gradient hypothesis (Mouritsen, 2003a; Holland, 2014; Guilford and de Perera, 2017). However, the character of the cues and proof for real presumption stay subtle. Earth's magnetic cues (angle of inclination, declination angle, and overall magnetic field intensity) offer anticipatable spatial gradients throughout huge sections of the globe and will serve for navigation. The navigational systems of different animal species are by a wide margin less notable as compared to birds. The magnetic compass and the solar compass seem to be the most common among diverse animal groups, vertebrates, and invertebrates. During bird migration, the celestial cues go through notable changes because of the latitude shift. Sunset cues alter their location with seasons and latitudes. The recognizable stars lose height and lastly vanish underneath the horizon, whereas new stars show up in the south. These new ones must be calibrated. As celestial rotation not imparting a reference, it isn't unexpected that the magnetic compass turns into the main cue, that controls the directional importance of stars and sunset cues. The geomagnetic field is an omnipresent solid factor that is accessible independent of climate conditions. Sun and star compasses share numerous significant highlights. The two of them require clear skies for application. The knowledge essential for both compass functioning is seen through the eyes. Sensitiveness towards polarized light is surely known in invertebrates (Horváth, 2014), yet very limited is thought concerning how vertebrates, inclusive of birds, perceive polarized light (Muheim, 2011; Horváth, 2014). There is no clear anatomical structure in the bird retina-specific for polarized light gathering, and no reasonable hypothesis exists on how birds, and most different vertebrates, can sense polarised light (Roberts et al., 2011). The courses acquired on the basis of the innate guidelines through the migratory headings were by no means straight and basic. As earlier proposed following ringing recoveries and observational evidences (Zink and Bairlein, 1995), and as of late depicted by the routes of migratory birds outfitted with gadgets such as transmitters, GPS recorders (Egevang et al., 2010), or geologgers (Bridge et al., 2013), numerous birds pick courses that stay away from enormous environmental hindrances, such as high mountain ranges, broadened ocean intersections, or deserts. Based on these barriers, the inborn intelligence creating the migratory course should be significantly more unpredictable. Landmarks could at a basic level be distinguished by any sense, and birds can utilize magnetic, visual, olfactory, audible landmarks as well as spatial memory.

\section{COMPASS SYSTEMS}

The role of Earth's magnetic field in directing bird migration had been proposed in the nineteenth century (Middendorf, 1855). Over the past 55 years, animal navigation has grown exponentially. Birds are a highly favoured group for orientation studies, and their directional preferences are well-known than a diverse group of vertebrates and invertebrates. In this review, we would present the summary of our current understanding about birds' navigation mechanisms, that focuses on the cues which help them to arrive at their intended destination. Infrequent experiments were conducted in the first half of the 20th century, well-organized studies of bird navigation started post 1950, with two findings that provided further opportunities for directional studies, particularly (1) The migrants often target their heading towards migratory goal when tested in captive conditions (Kramer, 1949) and (2) The pigeons shifted from their homes, when released, often disappeared to point home (Matthews, 1951). Currently, there are a number of natural environment cues being suggested, yet because it is omnipresent, the geomagnetic field remains among the most talked about (Holland, 2014; Kishkinev, 2015; Mouritsen, 2018). Total magnetic field strength, the inclination angle (angle between field lines and surface of the Earth), and magnetic declination (angle between directions to magnetic and geographic North) can assist birds to establish a position (Mouritsen, 2013; Chernetsov et al., 2017). The ability to perceive headings, a referenced direction, inclusive of magnetic North $(\mathrm{mN})$ and/or geographical North $(\mathrm{gN})$, should be resolved so that a bird would perform orientation in the favoured direction. Magnetic declination is a top notch longitudinal (east-west position) cue in certain regions of the globe, and skilled Eurasian reed warblers, Acrocephalus scirpaceus appear to apply angle of declination as a component of map guidance in order to decide longitude (Chernetsov et al., 2017). Moreover, both stellar and sun compass must be learnt (Emlen, 1970, 1975a; Wiltschko and Wiltschko, 1981a), they are not inborn, in contrast to the magnetic compass. In any case, a really necessary feature isn't common between the two compasses: the sun compass is time-dependent with a synchro- 
Tyagi, T. and Bhardwaj, S. K. / J. Appl. \& Nat. Sci. 13(2), 627 - 640 (2021)

nous interior clock, while the star-based compass is essentially time-autonomous.

\section{Magnetic compass}

A compass is a simple instrument, usually just a dial with a magnetic needle that relies on the magnetic field polarity to point towards the magnetic north. The magnetic compass in migratory birds does not distinguish between magnetic north and south (difference focusing upon the polarity) but between poleward, wherein the magnetic field lines are sloping, and equatorward, wherein they are facing upwards. Their magnetic inclination compass responds to the direction of the field lines and ignores the polarity of the geomagnetic field (Wiltschko and Wiltschko, 2015). Magnetic compass orientation was first described in European robins, Erithacus rubecula in caged experiments (Merkel and Wiltschko, 1965; Wiltschko, 1968). Close to the magnetic equator, the strength of the geomagnetic field is decreased by one-half (less than 25,000 nT) in comparison with polar places (greater than 68,000 nT) and over there, magnetic field lines are aligned along the parallel plane (Skiles, 1985). Another significant characteristic of a bird's magnetic compass is that its only function in a specific operational range, e.g., the magnetic field should not be too weak or too strong compared with the surrounding field. An increase or decrease in the magnetic field strength over and above $25-30 \%$ has led to confused orientation (Wiltschko, 1978; Wiltschko et al., 2007). Birds during experiments have demonstrated to acclimatize with decreased magnetic field strength, recommending that the magnetic compass was adjusted accordingly (Wiltschko, 1978; Wiltschko and Wiltschko, 1995a). Two magnetic field detecting theories are upheld by solid information: light-reliant radical pair-based magnetoreception (Ritz et al., 2000; Maeda et al., 2008; Ritz et al., 2009; Zapka et al., 2009) and trigeminal nerve intervened, presumably iron-mineral-based, magnetoreception (Falkenberg et al., 2010; Heyers et al., 2010). The third theory was suggested that included the inner ear lagena (Zhao et al., 2009; Wu and Dickman, 2011). In 1882, Viguier predicted that "the geomagnetic field determines, within the endolymph of the canals, induced currents, whose intensities vary dependently of both the canals' positions in relation to inclination and declination, and the intensity of the magnetic field" (Viguier, 1882). Recent studies on experimental basis and by actual computation showed that pigeons perceive magnetic fields inside the semicircular canals of inner ear by means of electromagnetic induction (Nimpf et al., 2019). The voltage-gated calcium channel (CaV1.3) in the pigeon's inner ear had been appeared to intervene electroreception in sharks and skates (Bellono et al., 2018).
European robins, Erithacus rubecula, and different passerines experimented under $373 \mathrm{~nm}$ UV (Ultraviolet), $424 \mathrm{~nm}$ blue, $502 \mathrm{~nm}$ turquoise, and 565 $\mathrm{nm}$ green light has shown directional preference towards their migratory destinations, however, were confused under $590 \mathrm{~nm}$ yellow and $635 \mathrm{~nm}$ and 645 $\mathrm{nm}$ red light (Wiltschko et al., 1993; Wiltschko and Wiltschko, 1995b, 1999; Rappl et al., 2000; Muheim et al., 2002; Wiltschko et al., 2011, 2014). A similar wavelength reliance is demonstrated in homing pigeons (Wiltschko and Wiltschko, 1998) and domestic chickens (Wiltschko et al., 2007). When pigeons were displaced in absolute darkness, they were unable to navigate and left randomly (Wiltschko and Wiltschko, 1981b). Migrating birds, as well, fail to do orientation in their expected migratory direction in darkness (Wiltschko et al., 2010). According to various studies, animals might see the magnetic field details of the light-based radical-pair process that occurs within the cryptochromes inside the bird retina (Ritz etal., 2000; Wiltschko et al., 2010; Hore and Mouritsen, 2016). Cryptochromes are well-known to perform a vital part in producing and keeping up circadian rhythms in flora and fauna (Chaves et al., 2011). Cryptochrome 4 is an especially alluring magnetosensory applicant since it ties flavin well (Qin et al., 2016; Günther et al., 2018). Besides, cryptochrome 4 is situated in double cones, which are two cones connected to one another that looks at a similar area in space and thus receive identical light input (Hore and Mouritsen, 2016; Günther et al., 2018). The brain region recognized as Cluster $\mathrm{N}$ is needed for directional orientation among nocturnal migrating songbirds (Mouritsen et al., 2005; Zapka et al., 2009). After lesioning the Cluster $\mathrm{N}$, the European robins could utilize solar compass and stellar compass, yet their magnetic compass becomes non-operational (Zapka et al., 2009). Conversely, when the ophthalmic branch of the trigeminal nerve is incised bi-laterally, birds were not able to correct for displacements, i.e., their map guidance becomes upset (Kishkinev et al., 2013). However, their magnetic compass stays unaffected (Zapka et al., 2009; Kishkinev et al., 2013).

About 139 years ago, it was first proposed that homing animals use magnetic guidance for the perception of bi -coordinate map (Viguier, 1882). True navigation (mapbased) has been described as the competency to identify a location with respect to a familiar target, depending solely upon knowledge obtained from a remote release site (Grifn, 1952; Able, 2001). A few test endeavours to upset homing accomplishment by fastening magnets on the animals were unsuccessful, and for example seabirds with glued magnets on the head demonstrated navigation that was just like the control birds, proposing that magnetic compass orientation 
was not fundamental for their accomplished homing (Mouritsen, 2003b; Bonadonna et al., 2005). In numerous regions around the globe, geomagnetic field strength and inclination angle usually varies with the north-south axis, while the angle of declination vary particularly alongside the east-west axis (National Centers for Environmental Information, 2020). However, this is in no way defines a precise global grid and in certain regions, like western Asia and north-eastern Europe, this basic relation separates, with the end goal that birds would need to get familiar with an additional difficult spatial connection among the cues enabling precise navigation (Boström et al., 2012). Recent studies have demonstrated that adult Eurasian reed warbler, Acrocephalus scirpaceus may have relied on two basic parameters (magnetic inclination and magnetic field intensity) that coordinated with the catch location better than the altered magnetic declination and decided their positions utilizing the initial two, disregarding the final remaining parameter. On the other hand, it is conceivable that the birds couldn't recognize the adjustment in magnetic declination (Kishkinev et al., 2021). The absence of reaction to change in declination, is predictable with other ongoing outcomes acquired by adult garden warbler, Sylvia borin a significant long distance migratory bird just like the reed warbler and experienced or juvenile European robins, Erithacus rubecula, additionally didn't respond to the declination manipulation (Chernetsov et al., 2020). The investigation on three bird species (Chernetsov et al., 2017, 2020) proposes the participation of magnetic declination-based map guidance among birds isn't yet completely recognized. We tested red-headed buntings, Emberiza bruniceps a long-distance night migrant in orientation funnels in the evening during spring migration. Simulated overcast test results in a northerly mean direction. Buntings were tested in the magnetic field whose horizontal component was deflected $120^{\circ}$ anticlockwise under simulated overcast sky and responded by shifting their orientation accordingly. The results depict that this PalaearcticIndian night migrant possesses a magnetic compass, and magnetic cues act as primary directional messengers (Tyagi and Bhardwaj, 2021). It ought to likewise be reported that day migrating birds have been shown to possess a magnetic compass (Munro and Wiltschko, 1993a; Åkesson et al., 2006) and among nonmigratory species such as zebra finches and domestic chickens (Voss et al., 2007; Wiltschko et al., 2007). For non-migrants, the complication is to promote orientation behavior. Other non-migratory species, such as zebra finches, Taeniopygia guttata or chickens are trained to select particular directional headings in conditioning tests (Freire et al., 2005; Voss et al., 2007). The ability to sense magnetic field among zebra finches resemble to that seen in night migratory birds and are consistent with the cryptochromes as a fundamental magnetoreceptor, recommending that light-based magnetoreception is a typical characteristic in all birds, including non-migrant species (Pinzon-Rodriguez and Muheim, 2017).

\section{Sun compass}

The sun compass is learnt and appears to depend upon the azimuthal position of the sun (Wiltschko et al., 1976). The sun gets across the sky throughout the day, in the northern side of the equator from the east by means of south toward the west and in the southern half of the globe from the east by means of north toward the west. Following the sun to get directional orientation implies that this movement should be considered and compensated. The sun compass orientation using mirrors was first described in European starling, Sturnus vulgaris in round cages (Kramer, 1950). Related to the sun is the skylight polarization pattern. At about $90^{\circ}$ with the sun's position, a most extreme band of nearly $70 \%$ polarization that blurs to the two sides, which change location with respect to the sun movement. During sunrise/sunset, the high polarization band starts right up from the horizon through the zenith and then down again. When utilizing the sun based compass, pigeons think about just the sun's azimuth and disregard its height above the horizon (Keeton, 1979). The sun compass is a learned aid to homing pigeons, when Europeans brought them to the southern hemisphere whereby the sun comes full circle through the north rather than through the south similar to their unique home domain: with no issues, they could build up a regular solar compass acclimated to their recent home (Wiltschko et al., 2000). The sun compass orientation mechanism is acquired through a magnetic compass based on cognition. Post set up, nonetheless, the solar compass turns into a free component. Grown-up pigeons could orient using their solar compass only since the magnetic compass was disturbed using magnets (Wiltschko et al., 1981). Among passerines such as Starlings (Hoffmann, 1954), several types of night migrants (Able and Dillon, 1977), and black-capped Chickadees, Parus atricapillus (Duff et al., 1998), proof for solar compass orientation has been detected through conditioning tests. The ontogeny of the solar compass was not demonstrated in birds except pigeons, yet they are intended to occur in the same manner. Birds appeared to improve orientation when they were able to access the setting sun and associated factors (Moore, 1978; Katz, 1985). Changing bird's vision of the sunset using mirrors has directed an equivalent change (Moore, 1982), and the study of clock-shift tests demonstrates that the sunset response is part of the solar compass (Able and Cherry, 1986; Helbig, 
Tyagi, T. and Bhardwaj, S. K. / J. Appl. \& Nat. Sci. 13(2), 627 - 640 (2021)

1991).

Inexperienced birds should notice and memorize the trajectory of the sun and should merge the azimuthal position of the sun with their circadian clock (Wiltschko et al., 1976). In daytime migratory birds, Zugunruhe likewise exists yet is hard to isolate from the diurnal activity, which without a doubt added to the shortage of investigations of directional preferences in daytime migrants tested in funnel cage experiments (Munro and Wiltschko, 1993a, 1993b). The genuine function of the sun in diurnal migrants, in any case, remained to a great extent obscure. However, it has been widely believed that the solar compass is a significant directional messenger of diurnal birds (Bellrose, 1972; Emlen, 1975b). Later investigations with day migrants, like meadow pipits, Anthus pratensis and European starlings, Sturnus vulgaris tested at the time of fall migration did not uphold this opinion. These birds did not illustrate a common deviation in response to the changes in their internal clock, which was seen in the experiment with the clock-shifted homing pigeons (SchmidtKoenig, 1972; Wiltschko, 1983). Although these diurnal migrants did not exhibit directional preferences when experimented with clock-shifted conditions under the sun, they prefer to orient under the cloudy sky (Helbig et al., 1987). It is only during the spring that the European starlings reply to a change within their internal clock with the anticipated variation (Wiltschko, 1981). These discoveries left the function of the solar compass quite uncertain while recommending that another compass system may be included. Clock-shift experiments with yellow-faced honey eaters, Lichenostomus chrysops too criticize a predominant function of the solar compass in their directional preferences (Munro and Wiltschko, 1993b). It has been proposed that the sun compass isn't utilized for migratory directional preferences by daytime migratory birds (Wiltschko and Wiltschko, 2015), in light of the fact that day-migrating birds in several tests didn't appear to depend upon the solar compass for orientation (Munro and Wiltschko, 1993b; Åkesson et al., 2006).

Scattering of unpolarized light penetrating the earth's atmosphere from the sun results in partially polarized skylight (Brines and Gould, 1982). While there may not be a clean proof that polarized light cues perform any part in the time-compensated solar compass directional orientation in birds, cue-calibration and cue-conflict studies with night migrants suggest that the polarized light pattern at sunset play a crucial part in making a decision towards departure direction (Moore, 1978; Able, 1982; Moore, 1986). In a magnetic field that did not give orientation information, polarized light patterns from sunset can be used as a directional guide: in the evening, night-flying birds having accessibility to the open sky are moving toward their migratory goals.
However, under depolarizers, similar birds were confused (Helbig, 1991). Migratory birds' behavioral experiments constantly reported the involvement of skylight polarization pattern in orientation (Moore and Phillips, 1988; Helbig and Wiltschko, 1989). Earlier studies show that visual guidance at sunset seems critical for direction preferences in nocturnal songbirds (Moore, 1987; Helbig, 1990). The polarized light pattern allowed to adjust directional preferences due to the unavailability of magnetic and sun-based cues (Munro and Wiltschko, 1995). Light from the natural sky is likewise consistently up to a certain extent polarized, except for absolutely cloudy or foggy weather (Cronin et al., 2006; Horváth et al., 2014).

\section{Star compass}

Since the earth orbits the sun, the sidereal day, for example, the time when a particular star appears in a similar location as earlier, is around four minutes short when compared with the sun-based day. As a result, the starry sky gradually moves throughout the seasons; the late spring sky is not quite the same as the winter sky. Birds that use stars to guide themselves must adapt to these changes. The star-based orientation was subsequently recognized as a star compass (Sauer, 1957). The stellar compass of night-migrants involves a learning process (Emlen, 1975a). Night migrants have no innate information on what the star patterns ought to resemble. Alternatively, in the Northern Hemisphere, birds inherited the characteristic to search for the rotating light dots throughout the open sky and to decipher the focal point of rotation as geographic North $(\mathrm{gN})$. More than seven starry nights appear to be required with the goal for birds to build up their stellar compass (Emlen, 1975a; Wiltschko et al., 1987; Michalik et al., 2014). Ontogenesis of the star-based compass in indigo buntings, Passerina cyanea is surprisingly complicated and utilization required remarkably sophisticated psychological skills, far more refined than the utilization of the magnetic compass, which typically surprises people most (Chernetsov, 2015). Indigo Buntings, Passerina cyanea turn around their directional preferences in response to switching of the planetarium sky (Emlen, 1967a,b). When the circannual cycle of certain indigo buntings was advanced and some others delayed so the two gatherings could have experimented together under a similar planetarium sky, the birds in vernal migratory condition oriented toward the north, those in fall condition oriented toward the south (Emlen, 1969a). These perceptions unmistakably demonstrated that the starry sky does not direct the orientation of birds. Changing the internal clock of birds didn't influence the directional preferences of birds tested under the open stellar sky (Matthews, 1963) or beneath the planetarium (Emlen, 1967b). This did not involve a pro- 
cess identical to solar-based compass and opposed the birds utilizing singular stars for direction. Rather it proposed that birds choose headings on the basis of consistent directional connection among the stars. Analogous to the solar compass, the stellar compass involves a learning process.

Inexperienced Indigo Buntings can be guided with the help of stars based on the condition that they were looking at the open sky prior to the fall migration (Emlen, 1969b). The celestial rotation has been found as an important aspect. Emlen (1970) hand raised two gatherings of birds beneath the planetarium sky; the test gathering was raised beneath a sky turning around Betelgeuse in Orion constellation; the control gathering was raised beneath an ordinary sky, turning around Polaris in Ursa Minor constellation. Experimented under the stationary planetarium sky during the fall migration, the control groups oriented toward their southerly destinations farther from the Polaris, while the other gathering oriented farther from the Betelgeuse. This certainly showed the significant part of the celestial rotation and the focal point of rotation in establishing the stellar compass. Similar investigations with other night migrants delivered similar outcomes (Katz and Michelsons, 1978), highlighting the contribution of the stars as directional messengers. Open sky tests upheld this wherein the birds during the nocturnal migration oriented without utilizing the magnetic details using only stars (Wiltschko and Wiltschko,1975a; Bingman, 1987). Sometimes the birds were indicated to get confused when they needed to depend on the stars for orientation (Moore, 1978; Pakhomov and Chernetsov, 2014). However, this does not really imply that they don't possess stellar compass; additionally, it could be a reaction to a specific test circumstance. Since most of the birds are diurnal, the star compass could only be used by birds that are nocturnal to perform orientation towards a specific migratory goal during prolonged night flights. The changes in the sky could be observed as the birds move southward during fall migration and the celestial pole with polar star descends and gets closer to the horizon, more difficult to see. New stars are emerging from the southern sky. These must be incorporated into the bird's cognitive ability towards the portrayal of stars. Thus, the magnetic compass seems to give a significant reference framework (Wiltschko and Wiltschko, 1975b). All things considered, when figuring out how to utilize a star compass, young birds recognize the focal point of celestial rotation by the snap-shot approach, for example, by contrasting the present stellar pattern with a remembered snap-shot in relation to a stationary landmark from the past event (Alert et al., 2015). The neurobiological system of memorizing the star compass merits examination furthermore.

\section{Landmarks, olfactory, retention of spatial cues en route}

The function of landmarks as a navigational cue at recognizable locations has regularly been talked about. At the point when the pigeons were denied of landmarks sighting by frosted (semi-opaque) lenses, this didn't influence their preliminary orientation and homing trip till they arrived at the space near their loft (Benvenuti and Fiaschi, 1983), with a few pigeons even attaining the home (Schlichte, 1973). In a broadened investigation of more releases with pigeons that were accustomed along with unaccustomed to the sites released on a rotational basis, distinction in deviation sizes were not noticed (Wiltschko et al., 2005). Landmarks perform a significant part essentially in the course of the final two stages of the navigation (the homing and goaltargeting stage). However prominent lines like coastlines, furthermore mountain ranges could likewise play a significant role as physical barriers in the longdistance stage (Dennis et al., 2007; Kullberg et al., 2007; Gagliardo, 2013; Gagliardo et al., 2013).

Odours assume a vital part in homing pigeons (Jorge et al., 2010; Gagliardo, 2013). Odour based map guidance likely gradient maps that serve knowledge solely about the course of displacement. A bird with a lack of experience can't be familiar with the smell of its goal situated far away. Subsequently, odour-based cues would probably be going to be significant at the time of homing and goal-targeting stages, yet could likewise assume a part during the long distance stage in skilled birds (Gagliardo, 2013; Gagliardo et al., 2013). In 1971, Papi and co-workers revealed that pigeons who lack in their ability to sense the smell showed more unfortunate starting direction, were slower in homing and a significant number of them were unsuccessful to return. The authors concluded that smells act as a navigational element: carried by the breeze, it would arrive at the pigeon from various headings that would later be related to the individual scent (Papi et al., 1971). Anosmia produced due to the treatment with zinc sulphate in experienced birds has a comparable disturbing impact because the birds no longer correct for displacement and reverted in their migratory direction (Holland et al., 2009). Studies published showed that pigeons oriented in their preferred directions when they smelled unnatural scents rather than the environmental ones. They proposed that smells didn't convey navigational data, however rather had an activation impact on the navigation systems (Jorge et al., 2009). A subsequent report (Jorge et al., 2010) backed this explanation. Nevertheless, a new monitoring investigation in Italy appeared to talk about the importance of environmental smell as a navigation cue (Gagliardo et al., 2011). Studies performed on Cory's shearwater, Calonectris borealis that 
Tyagi, T. and Bhardwaj, S. K. / J. Appl. \& Nat. Sci. 13(2), 627 - 640 (2021)

breeds in the Azores have shown an important role of olfaction over the spread-out ocean. Investigation was carried out in the Mediterranean Sea, where the accessibility of landmarks could offer a substitute for navigation towards homing. Magnet glued shearwaters and control birds headed towards home even if the coastal region was invisible and quickly went home. Anosmic shearwaters perform orientation in a very different direction from their home in the open sea. After moving closer to the coast, their flight route altered from the complicated to the home orientation, so that a large portion of them, at last, arrived at home. In addition to confirming that magnetic cues seem to be insignificant in seabirds navigation, these findings support the involvement of olfactory cues during bird navigation and suggest that anosmic shearwaters can home at last by following coastal landmarks (Pollonara et al., 2015).

Field studies have revealed that, in certain species, a considerable extent of individuals get back to similar breeding, overwintering, and stopover areas in progressive years. The finding proposes that migratory birds have advanced uncommon cognitive capacities that empower them to achieve these accomplishments. Results demonstrate that retention of a specific feeding place among adult garden warbler, Sylvia borin, a longdistance migratory bird lasted for a period of twelve months, while a firmly related non-migrant Sardinian warbler, Sylvia melanocephala momus could recall such place for just two weeks. In this manner, it appears to be that the migratory way of life has impacted the learning and remembering limits of migratory birds (Mettke-Hofmann and Gwinner, 2003). Hippocampus is the area of the brain considered to be engaged in the handling of spatial information. The comparative size of the hippocampal volume of migratory adult garden warblers is bigger than that of inexperienced juveniles of identical species. No similar comparison in hippocampal volume between older and younger birds was established in the firmly related non-migratory Sardinian warbler. These discoveries are persistent with the speculation that migratory birds procure spatial data about the course and stopover locations upholding the view that adjustments in the hippocampus might be related to migratory experience (Healy et al., 1996) and, most generally, with research signifying a comparably larger hippocampal volume in birds that clearly depends upon retention of spatial information (Healy et al., 1994; Reboreda et al., 1996; Volman et al., 1997).

\section{INTERACTIONS AND HIERARCHY BETWEEN CELESTIAL AND MAGNETIC CUES}

During spring migration, the magnetic field is consistently predominant, as the conduct of birds captured on their overwintering quarters experimentally demon- strates (Wiltschko and Wiltschko, 1975a; Bingman, 1987; Bingman and Wiltschko, 1988; Able and Able, 1996; Wiltschko et al., 1998). Routes of clock-shifted pigeons uncovered a lot of individual variability in where and when they revised their course and returned to their loft. They do not appear to surrender the sun compass entirely, nonetheless, only minimizing the dependency: until they reach their home, their more extended courses will generally be diverted to the normal side (Gagliardo et al., 2009; Schiffner et al., 2014). At the completion of the subjective day, clock-shift pigeons generally make a stoppage and subsequently resumed their orientation towards their home; pigeons with little magnets on the head halted and departed towards confused routes (Gagliardo et al., 2009). The geomagnetic compass seems to assume control when pigeons understand that their solar compass is out of order. Studies have shown that solar and stellar compass are secondarily acquired from the magnetic compass and skylight polarization patterns (Phillips and Moore, 1992; Muheim et al., 2007). This fundamental calibration reference would furnish birds with an outright, geographic directional framework, which is autonomous of latitude and season. The European diurnal migrant, Tree Pipits, Anthus trivialis, experimented under open skies during sunset and pursued a rotated magnetic North, apparently neglecting the sunset (Åkesson et al., 2006). Birds that were over and again experimented in a similar cue-conflict situation. Nonetheless, at last, all the cases pursued the magnetic field; here, dominance was shown by the magnetic cues. However, there are dissimilarities among the different birds' such as three species of Sylvia-warblers, Dunnock, Prunella modularis reacted quickly to the shifted magnetic North (Wiltschko and Wiltschko, 1975b; Bingman and Wiltschko, 1988), while European Robins reacted uniquely with a delayed behaviour, following the rotated magnetic North during the third or fourth test (Wiltschko and Wiltschko, 1975a; Bingman, 1987). The Australian silver eyes, Zosterops lateralis performing migration at nightfall and sunrise, reacted to an anticlockwise rotated magnetic North without delay, yet in clockwise rotation the response was delayed (Wiltschko et al., 1998).

At certain places, particularly close to the polar region, bird migrants encounter a dispute in choosing the headings provided by the solar and star compass contrasted with the magnetic compass, as magnetic declination displays significant differences in adjacent areas (Skiles, 1985). Birds are intended to re-calibrate their compasses to adapt to these troubles, both during ontogeny and adult life (Able and Able, 1993, 1995; Muheim et al., 2003). It is usually accepted that prior to the beginning of the first migration, celestial rotation helps in the calibration of the magnetic compass (Wiltschko, 
2017). The criterion of cue calibration in the course of migration seems inconsistent: a few research recommended that the magnetic compass helps in calibrating the celestial cues (Sandberg et al., 1991; Wiltschko et al., 1998; Wiltschko et al., 1999a, 1999b; Sandberg et al., 2000; Wiltschko et al., 2001a, 2001b), while others confirmed an opposite pattern (Cochran et al., 2004; Muheim et al., 2006a, 2006b, 2009). Two species were tested in order to determine the consequences on the magnetic cues, and here, the outcomes differ: Savannah sparrows, Passerculus sandwichensis seemed to have re-calibrated their magnetic compass (Able and Able, 1995), though, in Silvereyes, the magnetic compass seemed unaltered (Wiltschko et al., 1999a). European Robins and Garden Warbler re-calibrated the celestial cues, for this situation the stars: in a vertical magnetic field not giving directional guidance, they show directional preferences on the basis of star compass alone towards the path wherein the shifted magnetic field had guided them (Wiltschko and Wiltschko, 1975a, 1975b). Silvereyes (Wiltschko et al., 1998) and Dunnocks (Bingman and Wiltschko, 1988) re-calibrated the cues from the setting sun. In Silvereyes, the recalibration was just powerful at dusk, the hour of the day during which birds encountered the cue conflict; their reaction to the particular cue at dawn was not affected (Wiltschko et al., 2001a). Sandberg et al. (2000) consolidated caged results with release tests: in the caged experiments just two bird species persuaded the shifted magnetic North. In release tests all four bird species reacted to this shift and the changed magnetic field guidance became ceased. At this point accessible, they clearly had re-calibrated the celestial cues. Some night migrating birds, for example, Swainson's thrushes, Catharus ustulatus, and grey-cheeked thrushes, $C$. minimus choose the course of migration based upon the data obtained from sunset cues. However, keep up the headings with the help of magnetic compass guidance (Cochran et al., 2004). The two types of North American sparrows namely the white-throated sparrows, Zonotrichia albicollis, and the savannah sparrows, Passerculus sandwichensis have been shown to re-calibrate their magnetic compass based on the skylight polarization pattern from the lower part of the sky close to the horizon (Muheim et al., 2006b, 2009), while different examinations have not been able to track down similar reaction in different types of passerines experimented in other geological areas (Wiltschko et al., 2008; Chernetsov et al., 2011; Åkesson et al., 2015). The birds are presumed to briefly move the recently calibrated magnetic compass knowledge to the accessible celestial compasses; and as soon as the starry sky becomes evident, the birds re-calibrate the stellar compass with consideration of the already recalibrated magnetic compass (Sjöberg and Muheim,
2016). Well-trained zebra finches, Taeniopygia guttata showed directional preferences when the polarized light axis is lined up parallel to the magnetic field. At the point when the polarized light axis was lined up perpendicularly to the magnetic field, the birds got confused. These discoveries are the primary proof for an immediate collaboration between polarized light and the lightbased magnetic compass in birds. They uncover an essentially new quality of the radical pair-based magnetoreceptor with a key impact on how birds see the Earth's magnetic field (Muheim et al., 2016).

\section{Conclusion}

The Earth's magnetic field, celestial (sun, skylight polarization pattern, and stars), landmarks, olfactory, and retention of spatial cues en route provide birds with compass knowledge during migration. The Earth's magnetic field is omnipresent, which can encourage birds to navigate. Still, bird magnetoreception is insufficiently recognized at various levels from the quantum biophysics of sensory systems, signalling pathways and neurophysiology in handling instructions within the brain. Behaviour tests are essential and can not avoid the likelihood. Disorientation emerges from impacts on bird motivation instead of fundamental magnetoreception occasions. The visual-brain routes are well-known in numerous birds, yet where celestial cues pertaining to orientation and navigation are explicitly processed within the brain regions of vertebrates was considerably less evident. This review asserts that any significant distance navigational undertaking will not be possible based on a single cue or mechanism, allowing birds to navigate with absolute precision over thousands of miles.

\section{ACKNOWLEDGEMENTS}

This study immensely appreciates the funding from the Department of Biotechnology, New Delhi, under the grant number BT/PR4984/MED/30/752/2012.

\section{Conflict of interest}

The authors declare that they have no conflict of interest.

\section{REFERENCES}

1. Able, K. P. (2001). The concepts and terminology of bird navigation. Journal of Avian Biology, 32(2), 174-183. https://doi.org/10.1034/j.1600-048X.2001.320211.x

2. Able, K. P. \& Able, M. A. (1993). Daytime calibration of magnetic orientation in a migratory bird requires a view of skylight polarization. Nature, 364(6437), 523-525. https:// doi.org/10.1038/364523a0

3. Able, K. P. \& Able, M. A. (1995). Interactions in the flexible 
Tyagi, T. and Bhardwaj, S. K. / J. Appl. \& Nat. Sci. 13(2), 627 - 640 (2021)

orientation system of a migratory bird. Nature, 375(6528), 230-232. https://doi.org/10.1038/375230a0

4. Able, K. P. \& Able, M. A. (1996). Migratory orientation: Autumn calibration of magnetic orientation is not evident in spring. Naturwissenschaften, 83, 517-518. https:// doi.org/10.1007/BF01141954

5. Able, K. P. \& Cherry, J. D. (1986). Mechanisms of dusk orientation in white-throated sparrows (Zonotrichia albicollis): Clock-shift experiments. Journal of Comparative Physiology A, 159(1), 107-113. https://doi.org/10.1007/ BF00612501

6. Able, K. P. \& Dillon, P. M. (1977). Sun Compass Orientation in a Nocturnal Migrant, the White-Throated Sparrow. The Condor, 79(3), 393-395. https://doi.org/10.2307/136 8027

7. Able, K.P. (1982). Skylight polarization patterns at dusk influence migratory orientation in birds. Nature, 299(5883), 550-551. https://doi.org/10.1038/299550a0

8. Åkesson, S., Odin, C., Hegedus, R., Ilieva, M., Sjoholm, C., Farkas, A. \& Horvath, G. (2015). Testing avian compass calibration: Comparative experiments with diurnal and nocturnal passerine migrants in South Sweden. Biology Open, 4(1), 35-47. https://doi.org/10.1242/bio.201498 37

9. Åkesson, S., Jonzén, N., Pettersson, J., Rundberg, M. \& Sandberg, R. (2006). Effects of magnetic manipulations on orientation: Comparing diurnal and nocturnal passerine migrants on Capri, Italy in autumn. Ornis Svecica, 16, 5561.

10. Alerstam, T., Chapman, J. W., Bäckman, J., Smith, A. D., Karlsson, H., Nilsson, C., Reynolds, D. R., Klaassen, R. H. G. \& Hill, J. K. (2011). Convergent patterns of longdistance nocturnal migration in noctuid moths and passerine birds. Proceedings of the Royal Society B: Biological Sciences, 278(1721), 3074-3080. https://doi.org/10.1098/ rspb.2011.0058

11. Alert, B., Michalik, A., Helduser, S., Mouritsen, H. \& Güntürkün, O. (2015). Perceptual Strategies of Pigeons to Detect a Rotational Centre-A Hint for Star Compass Learning? PLOS ONE, 10(3), e0119919. https:// doi.org/10.1371/ journal.pone.0119919

12. Bellono, N. W., Leitch, D. B. \& Julius, D. (2018). Molecular tuning of electroreception in sharks and skates. Nature, 558(7708), 122-126. https://doi.org/10.1038/s41586-0180160-9

13. Bellrose, F. C. (1972). Possible steps in the evolutionary development of birds' navigation. In S. R. Galler, K. Schmidt-Koenig, G. J. Jacobs \& R. E. Belleville (Eds.), Animal Orientation and Navigation: Vol. NASA SP-262 (pp. 223-258). US Government Printing Office.

14. Benvenuti, S. \& Fiaschi, V. (1983). Pigeon homing: Combined effect of olfactory deprivation and visual impairment. Comparative Biochemistry and Physiology Part A: Physiology, 76(4), 719-723. https://doi.org/10.1016/0300-9629 (83)90133-0

15. Berthold, P. (1999). A comprehensive theory for the evolution, control and adaptability of avian migration. Ostrich, 70(1), 1-11. https://doi.org/10.1080/00306525.1999.963 9744

16. Bingman, V. P. (1987). Earth's Magnetism and the Nocturnal Orientation of Migratory European Robins. The Auk, 104(3), 523-525. https://doi.org/10.2307/4087555
17. Bingman, V. P. \& Wiltschko, W. (1988). Orientation of Dunnocks (Prunella modularis) at Sunset. Ethology, 77(1), 1-9. https://doi.org/10.1111/j.1439-0310.1988.tb00187.x

18. Bonadonna, F., Bajzak, C., Benhamou, S., Igloi, K., Jouventin, P., Lipp, H. P. \& Dell'Omo, G. (2005). Orientation in the wandering albatross: Interfering with magnetic perception does not affect orientation performance. Proceedings of the Royal Society B: Biological Sciences, 272 (1562), 489-495. https://doi.org/10.1098/rspb.2004.2984

19. Boström, J. E., Åkesson, S. \& Alerstam, T. (2012). Where on earth can animals use a geomagnetic bi-coordinate map for navigation? Ecography, 35(11), 1039-1047. https://doi.org/10.1111/j.1600-0587.2012.07507.x

20. Bridge, E., Kelly, J., Contina, A., Gabrielson, R., MacCurdy, R. \& Winkler, D. (2013). Advances in tracking small migratory birds: A technical review of light-level geolocation. Journal of Field Ornithology, 84, 121-137. https://doi.org/10.1111/jofo.12011

21. Brines, M. L. \& Gould, J. L. (1982). Skylight Polarization patterns and Animal Orientation. Journal of Experimental Biology, 96(1), 69-91.

22. Chaves, I., Pokorny, R., Byrdin, M., Hoang, N., Ritz, T., Brettel, K., Essen, L.-O., van der Horst, G. T. J., Batschauer, A. \& Ahmad, M. (2011). The Cryptochromes: Blue Light Photoreceptors in Plants and Animals. Annual Review of Plant Biology, 62(1), 335-364. https:// doi.org/10.1146/annurev-arplant-042110-103759

23. Chernetsov, N. (2015). Avian compass systems: Do all migratory species possess all three? Journal of Avian Biology, 46(4), 342-343. https://doi.org/10.1111/jav.00593

24. Chernetsov, N., Kishkinev, D., Kosarev, V. \& Bolshakov, C. V. (2011). Not all songbirds calibrate their magnetic compass from twilight cues: A telemetry study. Journal of Experimental Biology, 214(15), 2540-2543. https:// doi.org/10.1242/ jeb.057729

25. Chernetsov, N., Kishkinev, D. \& Mouritsen, H. (2008). A Long-Distance Avian Migrant Compensates for Longitudinal Displacement during Spring Migration. Current Biology, 18(3), 188-190. https://doi.org/10.1016/j.cub.2008.0 1.018

26. Chernetsov, N., Pakhomov, A., Davydov, A., Cellarius, F. \& Mouritsen, H. (2020). No evidence for the use of magnetic declination for migratory navigation in two songbird species. PLOS ONE, 15(4), e0232136. https:// doi.org/10.1371/journal.pone. 0232136

27. Chernetsov, N., Pakhomov, A., Kobylkov, D., Kishkinev, D., Holland, R. A. \& Mouritsen, H. (2017). Migratory Eurasian Reed Warblers Can Use Magnetic Declination to Solve the Longitude Problem. Current Biology, 27(17), 2647-2651.e2. https://doi.org/10.1016/j.cub.2017.07.024

28. Cochran, W. W., Mouritsen, H. \& Wikelski, M. (2004). Migrating Songbirds Recalibrate Their Magnetic Compass Daily from Twilight Cues. Science, 304(5669), 405-408. https://doi.org/10.1126/science.1095844

29. Cronin, T. W., Warrant, E. J. \& Greiner, B. (2006). Celestial polarization patterns during twilight. Applied Optics, 45 (22), 5582-5589. https://doi.org/10.1364/ AO.45.005582

30. Dennis, T. E., Rayner, M. J. \& Walker, M. M. (2007). Evidence that pigeons orient to geomagnetic intensity during homing. Proceedings of the Royal Society B: Biological Sciences, 274(1614), 1153-1158. https://doi.org/10.1098/ rspb.2007.3768 
31. Duff, S. J., Brownlie, L. A., Sherry, D. F. \& Sangster, M (1998). Sun compass and landmark orientation by blackcapped chickadees (Parus atricapillus). Journal of Experimental Psychology: Animal Behavior Processes, 24(3), 243-253. https://doi.org/10.1037/0097-7403.24.3.243

32. Egevang, C., Stenhouse, I. J., Phillips, R. A., Petersen, A., Fox, J. W. \& Silk, J. R. D. (2010). Tracking of Arctic terns Sterna paradisaea reveals longest animal migration. Proceedings of the National Academy of Sciences of the United States of America, 107(5), 2078-2081. https://doi.org/1 0.1073/pnas.0909493107

33. Emlen, S. T. (1967a). Migratory Orientation in the Indigo Bunting, Passerina cyanea: Part I: Evidence for Use of Celestial Cues. The Auk, 84(3), 309-342. https:// doi.org/10.2307/4083084

34. Emlen, S. T. (1967b). Migratory Orientation in the Indigo Bunting, Passerina cyanea. Part II: Mechanism of Celestial Orientation. The Auk, 84(4), 463-489. https:// doi.org/10.2307/4083330

35. Emlen, S. T. (1969a). Bird Migration: Influence of Physiological State upon Celestial Orientation. Science, 165 (3894), 716-718. https://doi.org/10.1126/science.165.389 4.716

36. Emlen, S. T. (1969b). The development of migratory orientation in young indigo bunting, Passerina cyanea. Living Bird, 8, 115-126.

37. Emlen, S. T. (1970). Celestial Rotation: Its Importance in the Development of Migratory Orientation. Science, 170 (3963), 1198-1201. https://doi.org/10.1126/ science.170.3 963.1198

38. Emlen, S. T. (1975a). The stellar-orientation system of a migratory bird. Scientific American, 233(2), 102-111. https://doi.org/10.1038/scientificamerican0875-102

39. Emlen, S. T. (1975b). Migration: Orientation and Navigation. In D. S. Farner \& J. R. King (Eds.), Avian Biology: Vol. V (pp. 129-219). London: Academic Press.

40. Falkenberg, G., Fleissner, G., Schuchardt, K., Kuehbacher, M., Thalau, P., Mouritsen, H., Heyers, D., Wellenreuther, G. \& Fleissner, G. (2010). Avian Magnetoreception: Elaborate Iron Mineral Containing Dendrites in the Upper Beak Seem to Be a Common Feature of Birds. PLoS ONE, 5(2), e9231. https://doi.org/10.1371/ journal.pone.0009231

41. Freire, R., Munro, U. H., Rogers, L. J., Wiltschko, R. \& Wiltschko, W. (2005). Chickens orient using a magnetic compass. Current Biology: CB, 15(16), R620-621. https:// doi.org/10.1016/j.cub.2005.08.017

42. Gagliardo, A. (2013). Forty years of olfactory navigation in birds. Journal of Experimental Biology, 216(12), 21652171. https://doi.org/10.1242/jeb.070250

43. Gagliardo, A., Bried, J., Lambardi, P., Luschi, P., Wikelski, M. \& Bonadonna, F. (2013). Oceanic navigation in Cory's shearwaters: Evidence for a crucial role of olfactory cues for homing after displacement. Journal of Experimental Biology, 216(15), 2798-2805. https://doi.org/10.1242/ jeb.085738

44. Gagliardo, A., loalè, P., Filannino, C. \& Wikelski, M. (2011). Homing Pigeons Only Navigate in Air with Intact Environmental Odours: A Test of the Olfactory Activation Hypothesis with GPS Data Loggers. PLoS ONE, 6(8), e22385. https://doi.org/10.1371/journal.pone.0022385

45. Gagliardo, A., Savini, M., De Santis, A., Dell'Omo, G. \& loalè, P. (2009). Re-orientation in clock-shifted homing pigeons subjected to a magnetic disturbance: A study with GPS data loggers. Behavioral Ecology and Sociobiology, 64(2), 289-296. https://doi.org/10.1007/s00265-009-0847-x

46. Grifn, D. R. (1952). Bird navigation. Biol. Rev. Camb. Philos. Soc., 27, 359-400.

47. Guilford, T. \& de Perera, T. B. (2017). An associative account of avian navigation. Journal of Avian Biology, 48(1), 191-195. https://doi.org/10.1111/jav.01355

48. Günther, A., Einwich, A., Sjulstok, E., Feederle, R., Bolte, P., Koch, K.-W., Solov'yov, I. A. \& Mouritsen, H. (2018). Double-Cone Localization and Seasonal Expression Pattern Suggest a Role in Magnetoreception for European Robin Cryptochrome 4. Current Biology: CB, 28(2), 211223.e4. https://doi.org/10.1016/j.cub.2017.12.003

49. Healy, S. D., Clayton, N. S. \& Krebs, J. R. (1994). Development of hippocampal specialisation in two species of tit (Parus spp.). Behavioural Brain Research, 61(1), 23-28. https://doi.org/10.1016/0166-4328(94)90004-3

50. Healy, S. D., Gwinner, E. \& Krebs, J. R. (1996). Hippocampal volume in migratory and non-migratory warblers: Effects of age and experience. Behavioural Brain Research, 81(1-2), 61-68. https://doi.org/10.1016/S01664328(96)00044-7

51. Helbig, A. J. \& Wiltschko, W. (1989). The skylight polarization patterns at dusk affect the orientation behavior of blackcaps, Sylvia atricapilla. The Science of Nature, 76(5), 227-229. https://doi.org/10.1007/BF00627697

52. Helbig, A. J. (1990). Are orientation mechanisms among migratory birds speciesospecific? Trends in Ecology and Evolution, 5(11), 365-367. https://doi.org/10.1016/01695347(90)90096-V

53. Helbig, A. J. (1991). Dusk orientation of migratory european robins, Erithacus rubecula: The role of sun-related directional information. Animal Behaviour, 41(2), 313-322. https://doi.org/10.1016/S0003-3472(05)80483-X

54. Helbig, A. J., Orth, G., Laske, V. \& Wiltschko, W. (1987). Migratory Orientation and Activity of the Meadow Pipit (Anthus pratensis): A Comparative Observational and Experimental Field Study. Behaviour, 103(4), 276-293.

55. Heyers, D., Zapka, M., Hoffmeister, M., Wild, J. M. \& Mouritsen, H. (2010). Magnetic field changes activate the trigeminal brainstem complex in a migratory bird. Proceedings of the National Academy of Sciences, 107(20), 9394-9399. https://doi.org/10.1073/pnas.0907068107

56. Hoffmann, K. (1954). Versuche zu der im Richtungsfinden der Vögel enthaltenen Zeitschätzung. [Experiments on the time sense used in direction-finding by birds.]. Zeitschrift Für Tierpsychologie, 11, 453-475. https://doi.org/10.1111/ j.1439-0310.1954.tb02169.x

57. Holland, R. A. (2014). True navigation in birds: From quantum physics to global migration: Bird navigation. Journal of Zoology, 293(1), 1-15. https://doi.org/10.1111/ jzo.12107

58. Holland, R. A., Thorup, K., Gagliardo, A., Bisson, I. A., Knecht, E., Mizrahi, D. \& Wikelski, M. (2009). Testing the role of sensory systems in the migratory heading of a songbird. Journal of Experimental Biology, 212(24), 40654071. https://doi.org/10.1242/jeb.034504

59. Hore, P. J. \& Mouritsen, H. (2016). The Radical-Pair Mechanism of Magnetoreception. Annual Review of Biophysics, 45(1), 299-344. https://doi.org/10.1146/annurev- 
Tyagi, T. and Bhardwaj, S. K. / J. Appl. \& Nat. Sci. 13(2), 627 - 640 (2021)

biophys-032116-094545

60. Horváth, G. (2014). Polarized Light and Polarization Vision in Animal Sciences. Springer Berlin Heidelberg. https://doi.org/10.1007/978-3-642-54718-8

61. Horváth, G., Barta, A. \& Hegedüs, R. (2014). Polarization of the Sky. In G. Horváth (Ed.), Polarized Light and Polarization Vision in Animal Sciences (pp. 367-406). Springer Berlin Heidelberg.

62. Jorge, P. E., Marques, A. E. \& Phillips, J. B. (2009). Activational Rather Than Navigational Effects of Odors on Homing of Young Pigeons. Current Biology, 19(8), 650654. https://doi.org/10.1016/j.cub.2009.02.066

63. Jorge, P. E., Marques, P. A. M. \& Phillips, J. B. (2010). Activational effects of odours on avian navigation. Proceedings of the Royal Society B: Biological Sciences, 277 (1678), 45-49. https://doi.org/10.1098/rspb.2009.1521

64. Katz, Y. B. (1985). Sunset and the orientation of European robins (Erithacus rubecula). Animal Behaviour, 33(3), 825 -828. https://doi.org/10.1016/S0003-3472(85)80016-6

65. Katz, Y. \& Michelsons, H. (1978). Influence of direction altering of stellar or magnetic meridians on orientation of European Robins in circular cages at planetarium. In $\mathrm{H}$. Mihelsons, P. Blüm \& J. Baumaris, Orientazija Ptiz (Orientierung der Vögel) (pp. 180-193). Riga: Zinatne.

66. Keeton, W. T. (1979). Avian Orientation and Navigation. Annual Review of Physiology, 41(1), 353-366. https:// doi.org/10.1146/annurev.ph.41.030179.002033

67. Kishkinev, D. (2015). Sensory mechanisms of longdistance navigation in birds: A recent advance in the context of previous studies. Journal of Ornithology, 156(1), 145-161. https://doi.org/10.1007/s10336-015-1215-4

68. Kishkinev, D., Chernetsov, N., Heyers, D. \& Mouritsen, H. (2013). Migratory Reed Warblers Need Intact Trigeminal Nerves to Correct for a 1,000 km Eastward Displacement. PLOS ONE, 8(6), e65847. https://doi.org/10.1371/ journal.pone.0065847

69. Kishkinev, D., Packmor, F., Zechmeister, T., Winkler, H.C., Chernetsov, N., Mouritsen, H. \& Holland, R. A. (2021). Navigation by extrapolation of geomagnetic cues in a migratory songbird. Current Biology, S096 0982221001160. https://doi.org/10.1016/j.cub.2021.01.0 51

70. Kramer, G. (1949). Über Richtungstendenzen bei der nächtlichen Zugunruhe gekäfigter Vögel. In E. Mayr \& E. Schüz (Eds.), Ornithologie als biologische Wissenschaft (pp. 269-283). Heidelberg.

71. Kramer, G. (1950). Weitere Analyse der Faktoren, welche die Zugaktivität des gekäfigten Vogels orientieren. Naturwissenschaften, 37(16), 377-378. https://doi.org/10.1007/ BF00626007

72. Kullberg, C., Henshaw, I., Jakobsson, S., Johansson, P. \& Fransson, T. (2007). Fuelling decisions in migratory birds: Geomagnetic cues override the seasonal effect. Proceedings of the Royal Society B: Biological Sciences, 274 (1622), 2145-2151. https://doi.org/10.1098/rspb.2007.0 554

73. Maeda, K., Henbest, K. B., Cintolesi, F., Kuprov, I., Rodgers, C. T., Liddell, P. A., Gust, D., Timmel, C. R. \& Hore, P. J. (2008). Chemical compass model of avian magnetoreception. Nature, 453(7193), 387-390. https://doi.org/1 $0.1038 /$ nature 06834

74. Matthews, G. V. T. (1951). The Experimental Investigation of Navigation in Homing Pigeons. Journal of Experimental
Biology, 28(4), 508-536.

75. Matthews, G. V. T. (1963). The astronomical basis of "nonsense" orientation. Proc. XIIIth Internat. Ornithol. Congr., Ithaca, N.Y., 1962, 415-429.

76. Merkel, F. W. \& Wiltschko, W. (1965). Magnetismus und Richtungsfinden zugunruhiger Rotkehlchen (Erithacus rubecula). 71-77.

77. Mettke-Hofmann, C. \& Gwinner, E. (2003). Long-term memory for a life on the move. Proceedings of the National Academy of Sciences, 100(10), 5863-5866. https:// doi.org/10.1073/pnas.1037505100

78. Michalik, A., Alert, B., Engels, S., Lefeldt, N. \& Mouritsen, H. (2014). Star compass learning: How long does it take? Journal of Ornithology, 155(1), 225-234. https:// doi.org/10.1007/s10336-013-1004-x

79. Middendorf, A. T. von. (1855). Die Isepiptesen Russlands. Grundlagen zur Erforschung der Zugzeiten und Zugrichtungen der Vögel Russlands. Buchdruckerei der K. Akademie der Wissenschaften.

80. Moore, F. R. (1978). Sunset and the orientation of a nocturnal migrant bird. Nature, 274(5667), 154-156. https:// doi.org/10.1038/274154a0

81. Moore, F. R. (1982). Sunset and the orientation of a nocturnal bird migrant: A mirror experiment. Behavioral Ecology and Sociobiology, 10(2), 153-155. https://doi.org/10.1 007/BF00300176

82. Moore, F. R. (1986). Sunrise, Skylight Polarization, and the Early Morning Orientation of Night-Migrating Warblers. The Condor, 88(4), 493-498. https://doi.org/10.2307/1 368277

83. Moore, F. R. (1987). Sunset and the Orientation Behaviour of Migrating Birds. Biological Reviews, 62(1), 65-86. https://doi.org/10.1111/j.1469-185X.1987.tb00626.x

84. Moore, F. R. \& Phillips, J. B. (1988). Sunset, skylight polarization and the migratory orientation of yellow-rumped warblers, Dendroica coronata. Animal Behaviour, 36(6), 1770-1778. https://doi.org/10.1016/S0003-3472(88)80116-7

85. Mouritsen, H. (2003a). Spatiotemporal Orientation Strategies of Long-Distance Migrants. In P. Berthold, E. Gwinner \& E. Sonnenschein (Eds.), Avian Migration (pp. 493513). Springer Berlin Heidelberg. https:// doi.org/10.1007/978-3-662-05957-9_34

86. Mouritsen, H. (2003b). Waved albatrosses can navigate with strong magnets attached to their head. Journal of Experimental Biology, 206(22), 4155-4166. https:// doi.org/10.1242/jeb.00650

87. Mouritsen, H. (2013). The Magnetic Senses. In C. Galizia \& P. Lledo (Eds.), Neurosciences-From Molecule to Behavior: $A$ university textbook (pp. 427-443). Springer.

88. Mouritsen, H. (2015). Sturkie's Avian Physiology (C. Scanes, Ed.). Elsevier.

89. Mouritsen, H. (2018). Long-distance navigation and magnetoreception in migratory animals. Nature, 558(7708), 50 -59. https://doi.org/10.1038/s41586-018-0176-1

90. Mouritsen, H., Feenders, G., Liedvogel, M., Wada, K. \& Jarvis, E. D. (2005). Night-vision brain area in migratory songbirds. Proceedings of the National Academy of Sciences, 102(23), 8339-8344. https://doi.org/10.1073/ pnas. 0409575102

91. Mouritsen, H., Heyers, D. \& Güntürkün, O. (2016). The Neural Basis of Long-Distance Navigation in Birds. Annual Review of Physiology, 78(1), 133-154. https://doi.org/1 
Tyagi, T. and Bhardwaj, S. K. / J. Appl. \& Nat. Sci. 13(2), 627 - 640 (2021)

0.1146/annurev-physiol-021115-105054

92. Muheim, R. (2011). Behavioural and physiological mechanisms of polarized light sensitivity in birds. Philosophical Transactions of the Royal Society B: Biological Sciences, 366(1565), 763-771. https://doi.org/10.1098/rstb.20 10.0196

93. Muheim, R., Åkesson, S. \& Alerstam, T. (2003). Compass orientation and possible migration routes of passerine birds at high arctic latitudes. Oikos, 103(2), 341-349. https://doi.org/10.1034/j.1600-0706.2003.12122.x

94. Muheim, R., Åkesson, S. \& Phillips, J. B. (2007). Magnetic compass of migratory Savannah sparrows is calibrated by skylight polarization at sunrise and sunset. Journal of Ornithology, 148(2), 485-494. https://doi.org/10.1007/ s10336-007-0187-4

95. Muheim, R., Bäckman, J. \& Åkesson, S. (2002). Magnetic compass orientation in European robins is dependent on both wavelength and intensity of light. Journal of Experimental Biology, 205(24), 3845-3856.

96. Muheim, R., Moore, F. R. \& Phillips, J. B. (2006a). Calibration of magnetic and celestial compass cues in migratory birds-A review of cue-conflict experiments. Journal of Experimental Biology, 209(1), 2-17. https:// doi.org/10.1242/jeb.01960

97. Muheim, R., Phillips, J. B. \& Åkesson, S. (2006b). Polarized Light Cues Underlie Compass Calibration in Migratory Songbirds. Science, 313(5788), 837-839. https:// doi.org/10.1126/science.1129709

98. Muheim, R., Phillips, J. B. \& Deutschlander, M. E. (2009) White-throated sparrows calibrate their magnetic compass by polarized light cues during both autumn and spring migration. Journal of Experimental Biology, 212(21), 3466 -3472. https://doi.org/10.1242/jeb.032771

99. Muheim, R., Sjöberg, S. \& Pinzon-Rodriguez, A. (2016). Polarized light modulates light-dependent magnetic compass orientation in birds. Proceedings of the National Academy of Sciences, 113(6), 1654-1659. https:// doi.org/10.1073/pnas.1513391113

100.Munro, U. \& Wiltschko, W. (1993a). Magnetic compass orientation in the yellow-faced honeyeater, Lichenostomus chrysops, a day migrating bird from Australia. Behavioral Ecology and Sociobiology, 32(2), 141-145. https:// doi.org/10.1007/ BF00164047

101.Munro, U. \& Wiltschko, R. (1993b). Clock-Shift Experiments with Migratory Yellow- Faced Honeyeaters, Lichenostomus Chrysops (meliphagidae), an Australian Day -Migrating Bird. Journal of Experimental Biology, 181(1), 233-244.

102.Munro, U. \& Wiltschko, R. (1995). The role of skylight polarization in the orientation of a day-migrating bird species. Journal of Comparative Physiology A, 177(3). https:// doi.org/10.1007/BF00192424

103.National Centers for Environmental Information. (2020). Maps of magnetic elements from the WMM2020. https:// www.ngdc.noaa.gov/geomag/WMM/image.shtml

104.Nimpf, S., Nordmann, G. C., Kagerbauer, D., Malkemper, E. P., Landler, L., Papadaki-Anastasopoulou, A., Ushakova, L., Wenninger-Weinzierl, A., Novatchkova, M., Vincent, P., Lendl, T., Colombini, M., Mason, M. J. \& Keays, D. A. (2019). A Putative Mechanism for Magnetoreception by Electromagnetic Induction in the Pigeon Inner Ear. Current Biology, 29(23), 4052-4059.e4. https:// doi.org/10.1016/j.cub. 2019.09.048

105.Pakhomov, A. \& Chernetsov, N. (2014). Early evening activity of migratory Garden Warbler Sylvia borin: Compass calibration activity? Journal of Ornithology, 155(3), 621-630. https://doi.org/10.1007/s10336-014-1044-x

106.Papi, F., Fiore, L., Fiaschi, V. \& Benvenuti, S. (1971). The Influence of Olfactory Nerve Section on the Homing Capacity of Carrier Pigeons. Monitore Zoologico Italiano Italian Journal of Zoology, 5(4), 265-267. https:// doi.org/10.1080/00269786. 1971.10736180

107.Phillips, J. B. \& Moore, F. R. (1992). Calibration of the sun compass by sunset polarized light patterns in a migratory bird. Behavioral Ecology and Sociobiology, 31(3), 189 -193. https://doi.org/10.1007/BF00168646

108.Pinzon-Rodriguez, A. \& Muheim, R. (2017). Zebra finches have a light-dependent magnetic compass similar to migratory birds. Journal of Experimental Biology, 220(7), 1202-1209. https://doi.org/10.1242/jeb.148098

109.Pollonara, E., Luschi, P., Guilford, T., Wikelski, M., Bonadonna, F. \& Gagliardo, A. (2015). Olfaction and topography, but not magnetic cues, control navigation in a pelagic seabird: Displacements with shearwaters in the Mediterranean Sea. Scientific Reports, 5(1), 16486. https:// doi.org/10.1038/srep16486

110.Qin, S., Yin, H., Yang, C., Dou, Y., Liu, Z., Zhang, P., Yu, H., Huang, Y., Feng, J., Hao, J., Hao, J., Deng, L., Yan, X., Dong, X., Zhao, Z., Jiang, T., Wang, H.-W., Luo, S.-J. \& Xie, C. (2016). A magnetic protein biocompass. Nature Materials, 15(2), 217-226. https://doi.org/10.1038/ nmat4484

111.Ramos, J. S. L., Delmore, K. E. \& Liedvogel, M. (2017). Candidate genes for migration do not distinguish migratory and non-migratory birds. Journal of Comparative Physiology A, 203(6), 383-397. https://doi.org/10.1007/s00359017-1184-6

112.Rappl, R., Wiltschko, R., Weindler, P., Berthold, P. \& Wiltschko, W. (2000). Orientation Behavior of Garden Warblers (Sylvia borin) Under Monochromatic Light of Various Wavelengths. The Auk, 117, 256-260. https:// doi.org/10.1642/0004-8038(2000)117[0256:OBOGWS] 2.0.CO;2

113.Reboreda, J. C., Clayton, N. S. \& Kacelnik, A. (1996). Species and sex differences in hippocampus size in parasitic and non-parasitic cowbirds. Neuroreport, 7(2), 505508. https://doi.org/10.1097/00001756-199601310-00031

114.Ritz, T., Adem, S. \& Schulten, K. (2000). A Model for Photoreceptor-Based Magnetoreception in Birds. Biophysical Journal, 78(2), 707-718. https://doi.org/10.1016/ S0006-3495(00)76629-X

115.Ritz, T., Wiltschko, R., Hore, P. J., Rodgers, C. T., Stapput, K., Thalau, P., Timmel, C. R. \& Wiltschko, W. (2009). Magnetic Compass of Birds Is Based on a Molecule with Optimal Directional Sensitivity. Biophysical Journal, 96(8), 3451-3457. https://doi.org/10.1016/j.bpj.2008.11.072

116.Roberts, N. W., Porter, M. L. \& Cronin, T. W. (2011). The molecular basis of mechanisms underlying polarization vision. Philosophical Transactions of the Royal Society B: Biological Sciences, 366(1565), 627-637. https:// doi.org/10.1098/rstb. 2010.0206

117.Salewski, V., Bairlein, F. \& Leisler, B. (2000). Recurrence of some palaearctic migrant passerine species in West Africa. Ringing and Migration, 20(1), 29-30. https:// 
Tyagi, T. and Bhardwaj, S. K. / J. Appl. \& Nat. Sci. 13(2), 627 - 640 (2021)

doi.org/10.1080/03078698.2000.9674224

118.Sandberg, R., Bäckman, J., Moore, F. R. \& Lõhmus, M. (2000). Magnetic information calibrates celestial cues during migration. Animal Behaviour, 60(4), 453-462. https://doi.org/10.1006/anbe.2000.1582

119.Sandberg, R., Ottosson, U. \& Pettersson, J. (1991). Magnetic orientation of migratory wheatears (Oenanthe oenanthe) in Sweden and Greenland. Journal of Experimental Biology, 155(1), 51-64.

120.Sauer, F. (1957). Die Sternenorientierung nächtlich ziehender Grasmücken (Sylvia atricapilla, borin und curruca). Zeitschrift Für Tierpsychologie, 14(1), 20-70. https:// doi.org/10.1111/j.1439-0310.1957.tb00525.x

121.Schiffner, I., Siegmund, B. \& Wiltschko, R. (2014). Following the sun: A mathematical analysis of the tracks of clock-shifted homing pigeons. Journal of Experimental Biology, 217(15), 2643-2649. https://doi.org/10.1242/ jeb.104182

122.Schlichte, H.-J. (1973). Untersuchungen über die Bedeutung optischer Parameter für das Heimkehrverhalten der Brieftaube. Zeitschrift Für Tierpsychologie, 32(3), 257-280. https://doi.org/10.1111/j.1439-0310.197 3.tb01105.x

123.Schmaljohann, H., Fox, J. \& Bairlein, F. (2012). Phenotypic response to environmental cues, orientation and migration costs in songbirds flying halfway around the world. Animal Behaviour, 84, 623-640. https:// doi.org/10.1016/j.anbehav.2012.06.018

124.Schmidt-Koenig, K. (1972). New experiments on the effect of clock-shifts on homing in pigeons. In S. R. Galler, K. Schmidt-Koenig, G. J. Jacobs \& R. E. Belleville (Eds.), Animal Orientation and Navigation: Vol. NASA SP-262 (pp. 275-282). US Government Printing Office.

125.Sjöberg, S. \& Muheim, R. (2016). A new view on an old debate: Type of cue-conflict manipulation and availability of stars can explain the discrepancies between cuecalibration experiments with migratory songbirds. Frontiers in Behavioral Neuroscience, 10. https:// doi.org/10.3389/fnbeh.2016.00029

126.Skiles, D. D. (1985). The geomagnetic field Its nature, history, and biological relevance. In J. L. Kirschvink, D. S. Jones \& B. J. MacFadden (Eds.), Magnetite Biomineralization and Magnetoreception in Organisms (Vol. 5, pp. 43 -102). Springer US. https://doi.org/10.1007/978-1-46130313-8_3

127.Tyagi, T. \& Bhardwaj, S. K. (2021). Magnetic compass orientation in a palaearctic-Indian night migrant, The redheaded bunting. Animals, 11(6), 1541. https://doi.o rg/10.3390/ani11061541

128.Viguier, C. (1882). Le sens de l'orientation et ses organes chez les animaux et chez l'homme. Revue Philosophique de La France et de l'Etranger, 1-36.

129.Volman, S. F., Grubb, Jr., T. C. \& Schuett, K. C. (1997). Relative Hippocampal Volume in Relation to Food-Storing Behavior in Four Species of Woodpeckers. Brain, Behavior and Evolution, 49(2), 110-120. https:// doi.org/10.1159/000112985

130.Voss, J., Keary, N. \& Bischof, H.-J. (2007). The use of the geomagnetic field for short distance orientation in zebra finches. Neuroreport, 18(10), 1053-1057. https:// doi.org/10.1097/WNR.0b013e32818b2a21

131.Wiltschko, R., Nohr, D. \& Wiltschko, W. (1981). Pigeons with a deficient sun compass use the magnetic compass. Science (New York, N.Y.), 214(4518), 343-345. https:// doi.org/10.1126/science.7280697

132.Wiltschko, R., Walker, M. \& Wiltschko, W. (2000). Suncompass orientation in homing pigeons: Compensation for different rates of change in azimuth? The Journal of Experimental Biology, 203(Pt 5), 889-894.

133.Wiltschko, R. (1981). Die Sonnenorientierung der Vögel. II. Entwicklung des Sonnenkompaß und sein Stellenwert im Orientierungssystem. Journal of Ornithology, 122(1), 1 -22. https://doi.org/10.1007/BF01643440

134.Wiltschko, R. (2017). Navigation. Journal of Comparative Physiology A, 203(6), 455-463. https://doi.org/10.1007/ s00359-017-1160-1

135.Wiltschko, R., Denzau, S., Gehring, D., Thalau, P. \& Wiltschko, W. (2011). Magnetic orientation of migratory robins, Erithacus rubecula, under long-wavelength light. Journal of Experimental Biology, 214(18), 3096-3101. https:// doi.org/10.1242/ jeb.059212

136.Wiltschko, R., Munro, U., Ford, H., Stapput, K., Thalau, P. \& Wiltschko, W. (2014). Orientation of migratory birds under ultraviolet light. Journal of Comparative Physiology. A, Neuroethology, Sensory, Neural, and Behavioral Physiology, 200(5), 399-407. https://doi.org/10.1007/s00359014-0898-y

137.Wiltschko, R., Munro, U., Ford, H. \& Wiltschko, W. (1999a). After-Effects of Exposure to Conflicting Celestial and Magnetic Cues at Sunset in Migratory Silvereyes Zosterops I. Lateralis. Journal of Avian Biology, 30(1), 5662. https://doi.org/10.2307/3677243

138.Wiltschko, R., Munro, U., Ford, H. \& Wiltschko, W. (2001a). Orientation in migratory birds: Time-associated relearning of celestial cues. Animal Behaviour, 62(2), 245 -250. https://doi.org/10.1006/anbe.2001.1751

139.Wiltschko, R., Munro, U., Ford, H. \& Wiltschko, W. (2008). Contradictory results on the role of polarized light in compass calibration in migratory songbirds. Journal of Ornithology, 149(4), 607-614. https://doi.org/10.1007/ s10336-008-0324-8

140.Wiltschko, R., Siegmund, B. \& Stapput, K. (2005). Navigational strategies of homing pigeons at familiar sites: Do landmarks reduce the deflections induced by clockshifting? Behavioral Ecology and Sociobiology, 59(2), 303 -312. https://doi.org/10.1007/s00265-005-0043-6

141.Wiltschko, R., Stapput, K., Thalau, P. \& Wiltschko, W. (2010). Directional orientation of birds by the magnetic field under different light conditions. Journal of The Royal Society Interface, 7(suppl_2), S163-S177. https:// doi.org/10.1098/rsif.2009.0367.focus

142.Wiltschko, R. \& Wiltschko, W. (1981a). The development of sun compass orientation in young homing pigeons. Behavioral Ecology and Sociobiology, 9(2), 135-141. https://doi.org/10.1007/BF00293584

143.Wiltschko, R. \& Wiltschko, W. (1995a). Magnetic Orientation in Animals. Springer-Verlag. https://doi.org/10.100 7/978-3-642-79749-1

144.Wiltschko, R. \& Wiltschko, W. (1998). Pigeon Homing: Effect of Various Wavelengths of Light During Displacement. Naturwissenschaften, 85(4), 164-167. https:// doi.org/10.1007/s001140050476

145.Wiltschko, R. \& Wiltschko, W. (2015). Avian Navigation: A Combination of Innate and Learned Mechanisms. Advanc- 
Tyagi, T. and Bhardwaj, S. K. / J. Appl. \& Nat. Sci. 13(2), 627 - 640 (2021)

es in the Study of Behavior, 47, 229-310. https:// doi.org/10.1016/bs.asb.2014.12.002

146.Wiltschko, W. \& Wiltschko, R. (1995b). Migratory orientation of European Robins is affected by the wavelength of light as well as by a magnetic pulse. Journal of Comparative Physiology A, 177(3), 363-369. https://doi.org/10.10 07/BF00192425

147.Wiltschko, W. \& Wiltschko, R. (1999). The effect of yellow and blue light on magnetic compass orientation in European robins, Erithacus rubecula. Journal of Comparative Physiology A, 184(3), 295-299. https://doi.org/10.10 $07 / \mathrm{s} 003590050327$

148.Wiltschko, W., Wiltschko, R., Munro, U. \& Ford, H. (1998). Magnetic versus celestial cues: Cue-conflict experiments with migrating silvereyes at dusk. Journal of Comparative Physiology A: Sensory, Neural, and Behavioral Physiology, 182(4), 521-529. https://doi.org/10.10 07/s003590050199

149.Wiltschko, W. (1968). Über den Einfluß statischer Magnetfelder auf die Zugorientierung der Rotkehlchen (Erithacus rubecula). Zeitschrift Für Tierpsychologie, 25(5), 537-558. https://doi.org/10.1111/j.1439-0310.1968.tb 00028.x

150.Wiltschko, W. (1978). Further Analysis of the Magnetic Compass of Migratory Birds. In Klaus Schmidt-Koenig \& W. T. Keeton (Eds.), Animal Migration, Navigation, and Homing (pp. 302-310). Springer. https:// doi.org/10.1007/978-3-662-11147-5_29

151. Wiltschko, W. (1983). Compasses used by birds. Comparative Biochemistry and Physiology Part A: Physiology, 76(4), 709-717. https://doi.org/10.1016/0300-9629(83) 90132-9

152.Wiltschko, W., Balda, R. P., Jahnel, M. \& Wiltschko, R. (1999b). Sun compass orientation in seed-caching corvids: Its role in spatial memory. Animal Cognition, 2(4), 215-221. https://doi.org/10.1007/s100710050042

153.Wiltschko, W., Daum, P., Fergenbauer-Kimmel, A. \& Wiltschko, R. (1987). The development of the star compass in garden warblers, Sylvia borin. Ethology, 74(4), 285-292. https://doi.org/10.1111/j.1439-0310.1987.tb 00 939.x

154.Wiltschko, W., Freire, R., Munro, U., Ritz, T., Rogers, L., Thalau, P. \& Wiltschko, R. (2007). The magnetic compass of domestic chickens, Gallus gallus. Journal of Experimental Biology, 210(13), 2300-2310. https:// doi.org/10.1242/jeb.004853

155.Wiltschko, W., Gesson, M. \& Wiltschko, R. (2001b). Mag- netic compass orientation of European robins under 565 nm green light. Naturwissenschaften, 88(9), 387-390. https://doi.org/10.1007/s001140100248

156.Wiltschko, W., Munro, U., Ford, H. \& Wiltschko, R. (1993). Red light disrupts magnetic orientation of migratory birds. Nature, 364(6437), 525-527. https:// doi.org/10.1038/364525a0

157.Wiltschko, W. \& Wiltschko, R. (1975a). The Interaction of Stars and Magnetic Field in the Orientation System of Night Migrating Birds. II. Spring experiments with European Robins (Erithacus rubecula). Zeitschrift Für Tierpsychologie, 39(1-5), 265-282. https://doi.org/10.1111/j.1439 $-0310.1975 . \mathrm{tb} 00912 . x$

158.Wiltschko, W. \& Wiltschko, R. (1975b). The interaction of stars and magnetic field in the orientation system of night migrating birds. I. Autumn experiments with European Warblers (gen. Sylvia). Zeitschrift Fur Tierpsychologie, 37 (4), 337-355. https://doi.org/10.1 111/j.1439-0310.197 5.tb00885.x

159.Wiltschko, W. \& Wiltschko, R. (1981b). Disorientation of inexperienced young pigeons after transportation in total darkness. Nature, 291(5814), 433-434. https://doi.org/1 $0.1038 / 291433 a 0$

160.Wiltschko, W., Wiltschko, R. \& Keeton, W. T. (1976). Effects of a "permanent" clock-shift on the orientation of young homing pigeons. Behavioral Ecology and Sociobiology, 1(3), 229-243. https://doi.org/10.1007/BF00300066

161.Wu, L.-Q. \& Dickman, J. D. (2011). Magnetoreception in an Avian Brain in Part Mediated by Inner Ear Lagena. Current Biology, 21(5), 418-423. https://doi.org/10.1016/ j.cub.2011.01.058

162.Zapka, M., Heyers, D., Hein, C. M., Engels, S., Schneider, N.-L., Hans, J., Weiler, S., Dreyer, D., Kishkinev, D., Wild, J. M. \& Mouritsen, H. (2009). Visual but not trigeminal mediation of magnetic compass information in a migratory bird. Nature, 461(7268), 1274-1277. https:// doi.org/10.1038/nature08528

163.Zhao, Y., Huang, Y.-N., Shi, L. \& Chen, L. (2009). Analysis of magnetic elements in otoliths of the macula lagena in homing pigeons with inductively coupled plasma mass spectrometry. Neuroscience Bulletin, 25(3), 101-108. https://doi.org/10.1007/s12264-009-0311-y

164.Zink, G. \& Bairlein, F. (1995). Der Zug europäischer Singvögel: Ein Atlas der Wiederfunde beringter Vögel (Vols. 1-5). Aula-Verlag. 